\section{The National Survey of Trabeculectomy. I. Sample and methods}

variation in practice. Failure to control intraocular pressure with topical medications was the main indication for surgery. Advanced glaucomatous visual field damage was present at the time of surgery in half the sample. Though most patients were operated on within 3 months of listing, almost a third of consultants considered the wait unacceptably long.

Key words Glaucoma, National survey, Trabeculectomy, Waiting times

Methods Consultant ophthalmologists performing trabeculectomy in the United Kingdom were studied. Four consecutive patients undergoing trabeculectomy under each consultant prior to 18 June 1996 were retrospectively sampled. Patients were followed prospectively and evaluated 6 and 12 months after surgery. Data were collected by self-administered postal questionnaires. To

B. Edmunds

Royal College of Ophthalmologists

London, UK

J.R. Thompson

Department of

Ophthalmology

Leicester University

Leicester, UK

J.F. Salmon

Oxford Eye Hospital

Oxford, UK

R.P. Wormald

Glaxo Department of

Ophthalmic Epidemiology

London, UK

Miss Beth Edmunds

Royal College of

Ophthalmologists

17 Cornwall Terrace

Regent's Park

London NW1 4OW, UK

Tel: +44 (0)1719350702

Fax: $+44(0) 1719359838$

e-mail:

beth@RCOphth2.win-uk.net

Funded by the Department of Health

Presented in part at the

Royal College of

Ophthalmologists Annual

Congress, 1997

Received: 2 October 1998 Accepted in revised form:

8 March 1999 determine the effects of selection and reporting bias a validation study of 14 randomly selected units was also conducted. Results Three hundred and eighty-two consultants recruited 1454 eligible patients for analysis. The mean age of patients was 69.2 years (standard deviation 10.9 ) and $51.7 \%$ were male. The underlying diagnosis was primary open angle glaucoma in $89.2 \%$, pseudoexfoliation glaucoma in $5.4 \%$, normal tension glaucoma in $3.8 \%$ and pigmentary glaucoma in $1.6 \%$. There was advanced visual field damage in $50.5 \%$ of the cohort by the time of listing. The main indications for surgery were failure of medication to control intraocular pressure in $57.1 \%$, progressive visual field loss in $26.5 \%$ and progressive optic disc damage in $4.8 \%$. Primary surgery was undertaken in $4.8 \%$ of patients. In $80 \%$ trabeculectomy was performed within 3 months of listing. However, almost a third of consultants considered individual patient's waiting time too long. Validation studies confirmed that systematic bias did not operate in the selection of patients for the survey or in the reporting of outcomes.

Conclusion The findings of this survey are representative of current practices of trabeculectomy by consultants throughout the United Kingdom and show considerable
Trabeculectomy is a common glaucoma operation and is performed by most ophthalmologists in the United Kingdom (UK). Though there are reports of the operative technique, its indications, modifications and outcomes, there are no national figures describing current practice patterns in the UK. A National Survey of Trabeculectomy was therefore conducted to examine the selection of patients for surgery, variations in operative technique and the outcomes and complications of trabeculectomy in a UK population.

This paper describes the methods used in the survey, levels of consultant activity, the process of patient selection for surgery, waiting times and the demographic and clinical characteristics of the patient sample. Future papers will discuss the outcomes and complications of trabeculectomy and variations in surgical technique.

\section{Methods}

All ophthalmology consultants performing trabeculectomy in the National Health Service (NHS) formed the sampling frame for this survey. Each participant retrospectively selected the four most recent consecutive trabeculectomy cases under their care prior to 18 June 1996. Follow-up data were collected prospectively at 6 and 12 months following trabeculectomy. Only patients with a diagnosis of primary open angle glaucoma (POAG), normal tension glaucoma (NTG), pseudoexfoliation glaucoma (PXE) or pigmentary glaucoma (PDS) on whom a standard trabeculectomy (i.e. not combined 
with another procedure) had been performed were eligible. Patients were excluded if they had undergone any previous surgery that involved the bulbar conjunctiva of the eye or were part of a trial involving the random allocation of treatment.

Data were collected by self-administered questionnaires that were mailed to consultants on four occasions. All questionnaires were piloted prior to administration. In all but the preliminary contact questionnaire, respondents were given the choice of completing the questionnaires on either a $3 \frac{1}{2} 2$-inch floppy disk or conventional paper format. For confidentiality purposes each patient and consultant were coded. All data were kept in accordance with the Data Protection Act.

A preliminary contact questionnaire identified those consultants performing trabeculectomy in the NHS. Details about their practice and number of trabeculectomies performed in the year prior to the survey were also collected. Three subsequent questionnaires dealt with the clinical course of those patients selected by participating consultants. The first of these concerned baseline and other clinical characteristics of the patients, details of the surgical procedure and details of the immediate post-operative course. Copies of two visual field tests were also collected for each patient: one from the time of diagnosis and one from the time of listing for surgery. These were graded by a masked independent observer to stage the severity of glaucomatous loss into one of four grades: normal, glaucomatous loss not threatening fixation (no defects within $5^{\circ}$ of fixation), advanced glaucomatous loss with fixation threatened or involved (defects within $5^{\circ}$ of fixation) and ungradable. Fields were deemed ungradable if they were unreliable or incorrect (incorrect eye or incorrect date). A second masked observer graded a sample of $15 \%$ of the fields. There was concordance in $83.2 \%$. The second and third questionnaires examined the outcomes at 6 months and 1 year post-operatively.

Consultants were grouped into one of three groups to reflect their response status: non-respondents (did not respond to preliminary contact questionnaire after three reminder letters and remailing of the questionnaire), non-participants (responded to preliminary contact questionnaire but did not recruit patients for subsequent questionnaires) and participants (recruited patients for the survey). A random sample of $40 \%$ of nonrespondents was interviewed by telephone using a proforma identical to the preliminary contact questionnaire to establish whether this group differed significantly from participants. Non-participants were also compared with participants using data from completed preliminary contact questionnaires.

To assess the effect of selection and reporting bias a validation study of $14(10 \%)$ randomly selected ophthalmology units in England and Wales was conducted. A masked observer selected four patients for each participating consultant in these units according to the study criteria. Those patients who were incorrectly included by participants were compared with those
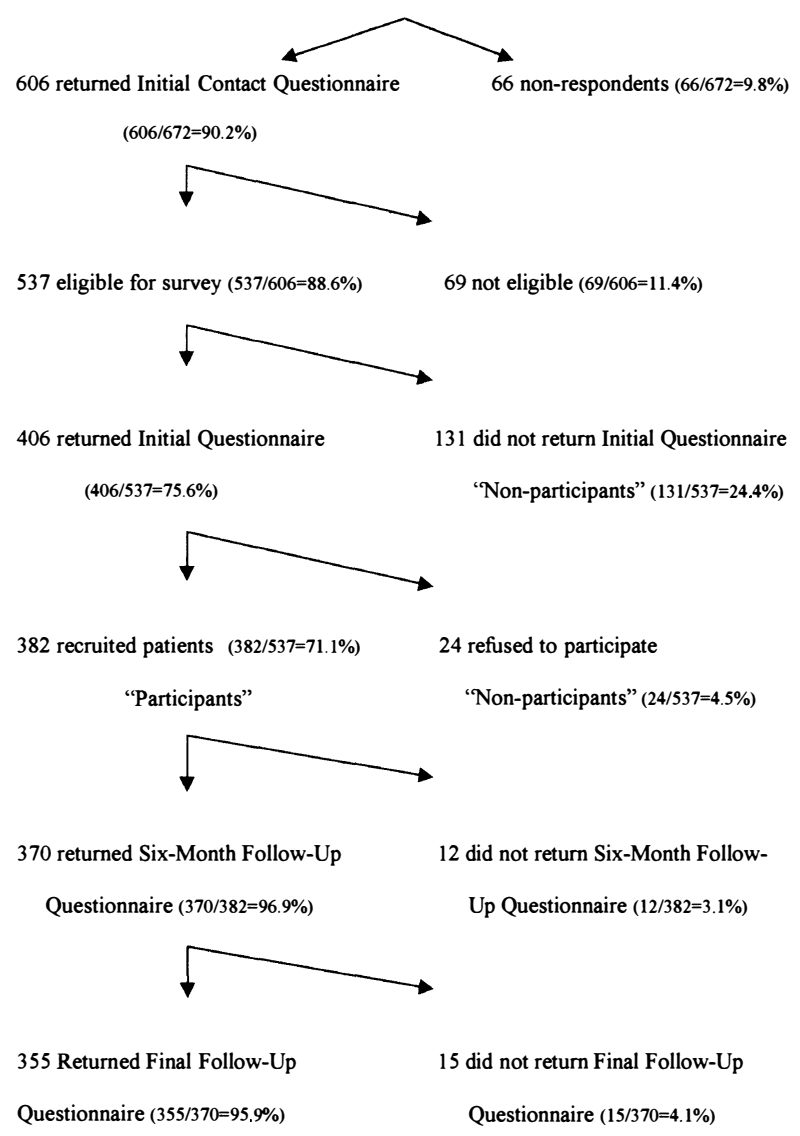

Fig. 1. Flowchart of consultant participation in the National Survey of Trabeculectomy.

patients who were incorrectly excluded for the following variables: age, sex, diagnosis, intraocular pressure (IOP) at diagnosis, listing and at first post-operative visit, visual acuity at listing, grade of surgeon, type of anaesthetic, use of antimetabolites and development of early post-operative complications.

Participants' reporting accuracy was assessed by comparing proformas completed by a masked observer with questionnaires completed by participants for five representative questions. The accuracy of participants' data reporting was scored as the proportion of answers correct when compared with those of the masked observer.

An activity analysis examining the variables reported in this paper as well as the outcomes of surgery was performed to identify any relationship with the level of activity of each consultant. Where significant associations were found consultants were divided into three groups according to the number of trabeculectomies they reported performing in the year prior to the survey: less than 21, 21 to 39 and greater than 39. Adjusted rates could thus be calculated and compared with reported rates.

Data were entered into a customised database and analysed using Microsoft Acccess for Windows 95 and SPSS (Statistical Package for Social Sciences, 1995). Data from the paper questionnaires were double entered; 


\begin{tabular}{|c|c|c|c|c|c|}
\hline Consultant interest & $\begin{array}{c}\text { No. of } \\
\text { consultants }\end{array}$ & $\begin{array}{l}\text { Percentage of } \\
\text { all eligible } \\
\text { consultants }\end{array}$ & $\begin{array}{l}\text { Median no. of } \\
\text { trabeculectomies } \\
\text { per consultant } \\
\text { per year }\end{array}$ & $\begin{array}{l}\text { Mean no. of } \\
\text { trabeculectomies } \\
\text { per consultant } \\
\text { per year }\end{array}$ & $\begin{array}{c}95 \% \text { confidence } \\
\text { intervals }\end{array}$ \\
\hline Glaucoma specialist & 121 & 22.5 & 42.0 & 54.0 & $45.4-62.6$ \\
\hline Non-specialist & 416 & 77.5 & 26.0 & 31.1 & $28.8-33.3$ \\
\hline All eligible consultants & 537 & 100 & 29.5 & 36.3 & $33.6-39.0$ \\
\hline
\end{tabular}

those from the computer disk version were downloaded directly into the database thus avoiding transcription error.

Internal validation checks, range checks and examination of outliers was performed. Continuous variables were analysed using Student's $t$-test, ANOVA or Mann-Whitney $U$ as appropriate. Chi-squared tests were used for categorical variables.

\section{Results}

Consultant response rates are presented in Fig. 1. Ninetyone per cent of all consultant ophthalmologists perform trabeculectomy in the NHS. Approximately 21600 trabeculectomies were performed in the year prior to the survey. The number of trabeculectomies performed by each consultant ranged from 0 to 250 with a mean of 36.3 trabeculectomies (95\% confidence interval (CI) 33.6-39.1) per consultant. Consultants with a specialist interest in glaucoma performed trabeculectomies at almost twice the frequency of those without a specialist glaucoma interest (Table 1).

One thousand four hundred and fifty-four patients were recruited. Six month follow-up data were available for $95.8 \%(n=1393)$ and 1 year follow-up data for $85.6 \%$ $(n=1244)$ of the cohort. (See Table 2 for reasons for failure of follow-up.)

The mean age of patients was 69.2 years (standard deviation (SD) 10.9) and 752 (51.7\%) were men. Ninetysix per cent were white. The underlying diagnosis was POAG in 1298 (89.2\%), PXE in 78 (5.4\%), NTG in 55 $(3.8 \%)$ and PDS in $23(1.6 \%)$. The mean IOP at diagnosis was $29.2 \mathrm{mmHg}$ (SD 7.5) and at listing was $26.4 \mathrm{mmHg}$ (SD 5.9) for the whole cohort, but differed significantly between the diagnostic categories $(p<0.0001)$. The age of each group also differed significantly between these categories $(p<0.0001)$ (Table 3).
The median time from diagnosis of glaucoma to surgery was 2.7 years with a range of 0-62 years. The stage of glaucoma, defined by the degree of visual field involvement, is presented in Table 4 . Advanced glaucomatous damage (central $5^{\circ}$ of fixation involved) was present in $35.3 \%$ of the cohort at diagnosis and $50.5 \%$ by the time of listing.

Fifty per cent of patients were on two topical medications in the operated eye at the time of listing for surgery. Fig. 2 shows the distribution of the number of topical medications. The percentage of patients on pilocarpine and/or adrenaline for longer than 6 months at some stage prior to surgery was $48.5 \%$.

Failure of medication to control IOP was cited as a consideration when listing the patient for trabeculectomy in $87.0 \%$ of cases. In 829 cases $(57.1 \%)$ it was given as the main reason for listing, and was the main and only reason in $23.3 \%$. Visual field deterioration contributed to the decision to operate in $48.8 \%$ of cases; in 385 (26.5\%) cases it was given as the main reason for listing, and was the main and only reason in $82(5.7 \%)$. Progressive optic disc changes influenced the decision to operate in $26.4 \%$, intolerance of medication in $15.0 \%$ and non-compliance in $6.6 \%$. Primary surgery was reported as the main reason for operating in $4.8 \%$ of the cohort. Figures for the main reason for operating are shown in Table 5.

The distribution of waiting times between listing and surgery is shown in Fig. 3. Trabeculectomy was performed in $81.4 \%$ of the group within 3 months of listing. However, in $43.8 \%$ of cases the patient waited longer than a time interval regarded acceptable by the consultant. If the acceptable waiting time is extended by 14 days to accommodate surgery performed close to this time limit, it was still regarded as unacceptably long by $28.2 \%$ of consultants. Although there was no significant difference in median waiting time between those cases treated by glaucoma specialists (52.0 days) compared

Table 2. Reasons for failure of follow-up at 6 months and 1 year after trabeculectomy

\begin{tabular}{lcccc}
\hline Reason & 6 months $^{\mathrm{a}}$ & 1 year $^{\mathrm{b}}$ & Total & $\begin{array}{c}\text { Percentage of cohort } \\
(n=1454)\end{array}$ \\
\hline Died & 18 & 12 & 30 & $2.1 \%$ \\
Lost to follow-up & 5 & 23 & 28 & $1.9 \%$ \\
Transferred & 12 & 2 & 14 & $1.0 \%$ \\
Notes lost & 7 & 5 & 12 & $0.8 \%$ \\
Discharged to optician & 2 & 0 & 2 & $0.1 \%$ \\
Discharged & 2 & 0 & 2 & $0.1 \%$ \\
Don't know & 1 & 1 & 2 & $0.1 \%$ \\
\hline
\end{tabular}

${ }^{a}$ Data available for 1393 cases $(95.8 \%)$.

${ }^{\mathrm{b}}$ Data available for 1244 cases $(85.6 \%)$. 


\begin{tabular}{|c|c|c|c|c|c|c|c|}
\hline Diagnosis & $\begin{array}{l}\text { No. of } \\
\text { patients }\end{array}$ & $\begin{array}{c}\text { Mean age } \\
\text { (years) }\end{array}$ & $95 \%$ CI & $\begin{array}{c}\text { Mean IOP } \\
\text { at diagnosis } \\
(\mathrm{mmHg})\end{array}$ & $95 \%$ CI & $\begin{array}{l}\text { Mean IOP } \\
\text { at listing } \\
(\mathrm{mmHg})\end{array}$ & $95 \%$ CI \\
\hline POAG & 1298 & 69.2 & $68.7-69.8$ & 29.5 & $29.0-29.9$ & 26.5 & $26.2-26.8$ \\
\hline PXE & 78 & 72.7 & $70.7-74.8$ & 31.6 & 29.3-33.9 & 29.5 & $27.8-31.2$ \\
\hline NTG & 55 & 69.2 & $66.2-72.3$ & 18.9 & $18.1-19.6$ & 20.0 & $18.8-21.1$ \\
\hline PDS & 23 & 53.6 & $46.7-60.4$ & 29.6 & $27.1-32.0$ & 25.8 & $23.3-28.3$ \\
\hline All patients & 1454 & 69.2 & $68.6-69.7$ & 29.2 & $28.8-29.6$ & 26.4 & $26.1-26.7$ \\
\hline
\end{tabular}

POAG, primary open angle glaucoma; PXE, pseudoexfoliation glaucoma; NTG, normal tension glaucoma; PDS, pigmentary glaucoma.

with non-specialists (50.0 days), consultants with a specialist interest were more likely to consider the waiting time unacceptable (35.2\% versus $26.1 \%$, $p=0.001)$.

\section{Results of non-respondent study}

Twenty-one of the 26 randomly selected nonrespondents were interviewed by telephone. Four consultants could not be contacted and one consultant was not eligible for the survey. There were no significant differences between participants and non-respondents or participants and non-participants for the variables of interest (Table 6).

\section{Results of validation studies}

Thirty-five consultants from 14 units had recruited 123 patients into the survey. Ninety-three $(79.5 \%)$ of 117 cases had been correctly included (6 sets of case notes were missing). Comparison of those patients incorrectly included with those incorrectly excluded showed no significant difference in the majority of variables examined. However, the group of patients incorrectly excluded were older $(p=0.014)$, more likely to be male $(p=0.004)$ and less likely to have had antimetabolite adjuvants at the time of surgery $(p=0.014)$. Reporting accuracy was $80 \%$ or more in $97 \%$ of cases. Full tabulation of these results is available on request.

\section{Activity analysis}

There was a significant association between the number of trabeculectomies performed in the year prior to the survey and the following variables: underlying diagnosis $(p=0.018)$, age $(p=0.050)$, waiting time $(p=0.005)$ and

Table 4. Stage of glaucoma at diagnosis and listing for surgery

\begin{tabular}{lccrrr}
\hline & \multicolumn{2}{c}{ At diagnosis } & & \multicolumn{2}{c}{ At listing } \\
\cline { 2 - 3 } \cline { 5 - 6 } Grade of visual field & No. & $\%$ & & No. & $\%$ \\
\hline Normal & 130 & 18.5 & & 72 & 7.4 \\
Glaucomatous & 324 & 46.2 & & 411 & 42.1 \\
Advanced & 248 & 35.3 & & 494 & 50.5 \\
Total gradable fields & 702 & 100 & & 977 & 100 \\
\hline
\end{tabular}

${ }^{a}$ Fields at diagnosis available for $743(51.1 \%)$ cases, 41 cases ungradable.

${ }^{\mathrm{b}}$ Fields at listing available for $1051(72.3 \%)$ cases, 74 cases ungradable. number of pre-operative drops $(p=0.016)$. One hundred and ten $(32.3 \%)$ consultants reported performing fewer than 21 trabeculectomies per year, $126(36.8 \%)$ between 21 and 39, and $106(31.0 \%)$ more than 39. Rates adjusted for these different levels of activity are compared with reported rates in Table 7 . The difference between the adjusted and reported rate is small for all variables except the proportion of NTG cases where the adjusted rate $(4.8 \%)$ is $26.3 \%$ greater than the reported rate $(3.8 \%)$.

\section{Discussion}

This survey was designed to examine current practices of trabeculectomy in the UK. In order to gain as representative a picture of UK practice as possible all consultant ophthalmologists who perform trabeculectomy in the NHS were sampled. A response rate to the preliminary initial contact questionnaire of $90 \%$ and subsequent participation of $71 \%$ of eligible consultants compares well with previous College audits. ${ }^{1,2}$ Limiting each consultant's contribution to 4 patients avoided overburdening those who perform trabeculectomy more frequently. A potential hazard of this sampling technique is the under-representation of those consultants who perform trabeculectomy more frequently. The activity analysis showed that for the majority of variables presented in this paper adjustment or weighting according to level of activity is not required. The strong correlation between number of

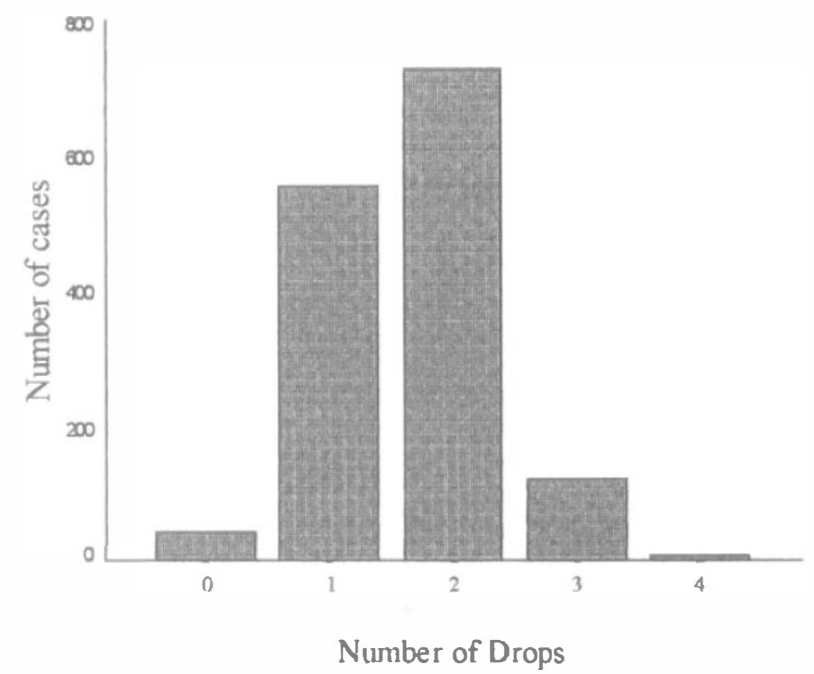

Fig. 2. Number of topical antiglaucoma medications in the operated eye at the time of listing. 
Table 5. Main reasons for listing for trabeculectomy

\begin{tabular}{|c|c|c|}
\hline Reason & $\begin{array}{c}\text { Main reason } \\
(\% \text { of total })\end{array}$ & $\begin{array}{l}\text { Main and } \\
\text { only reason } \\
\text { (\% of total) }\end{array}$ \\
\hline Failure of medication to control IOP & $829(57.1)$ & $338(23.3)$ \\
\hline Visual field deterioration & $385(26.5)$ & $82(5.7)$ \\
\hline Primary surgery & $70(4.8)$ & $32(2.2)$ \\
\hline Progressive disc changes & $67(4.6)$ & $14(1.0)$ \\
\hline Intolerant of medication & $56(3.9)$ & $17(1.2)$ \\
\hline Non-compliance & $17(1.2)$ & $3(0.2)$ \\
\hline Other & $18(1.2)$ & $8(0.6)$ \\
\hline Don't know & $10(0.7)$ & \\
\hline Total & $1452^{\mathrm{a}}(100.0)$ & $494(34.0)$ \\
\hline
\end{tabular}

${ }^{\mathrm{a}}$ Data missing for 2 cases.

trabeculectomies performed per year and the proportion of NTG cases suggests that trabeculectomy in NTG patients is more likely to be performed by consultants who operate more frequently. Adjusting for this correlation, however, does not change the clinical significance of the results and unadjusted figures are therefore presented. A follow-up of 1 year was felt to be sufficient to determine the success of surgery in terms of $\mathrm{IOP}^{3,4}$ and the development of most complications.

The study design incorporated retrospective patient selection, to minimise the Hawthorne effect, ${ }^{5}$ and prospective follow-up. It is possible, however, that awareness of early outcomes at the time of recruiting patients may have introduced selection bias. The validation study showed that $80 \%$ of patients were correctly selected. Comparison of the $20 \%$ incorrectly selected with those incorrectly excluded showed no difference for the majority of variables. The two groups did differ significantly for three variables: the group of patients incorrectly excluded were older, more likely to be male and less likely to have had antimetabolite adjuvants at the time of surgery. The difference in antimetabolite use may be explained by the age difference between the two groups, as antimetabolite use is less likely in older patients. The age and sex differences are best explained by random effects and are unlikely to represent an underlying difference between the groups. Comparison of respondents' questionnaires with case notes for inaccuracies in data retrieval showed an

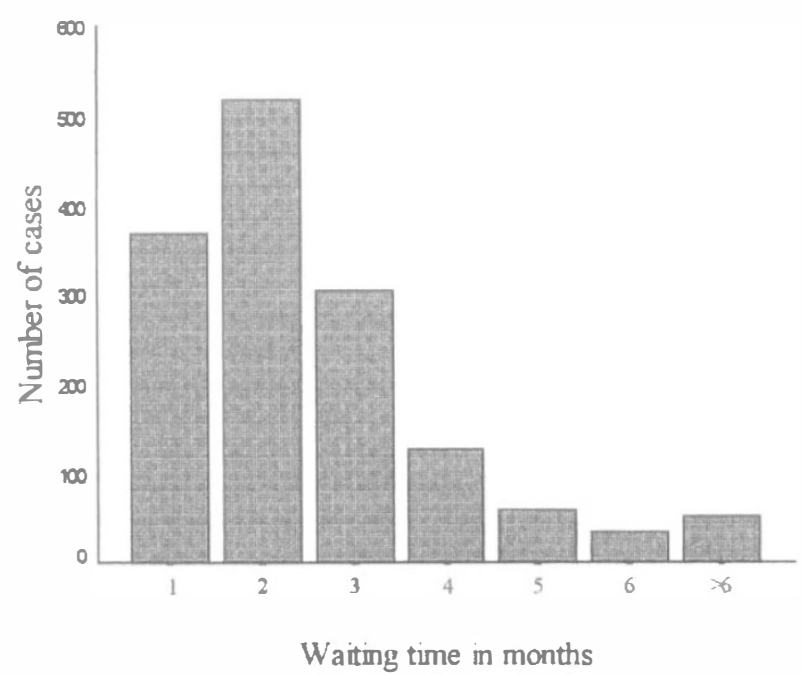

Fig. 3. Waiting time: time interval between listing and trabeculectomy.

accuracy of $80 \%$ or more in $97 \%$ of cases. Reporting inaccuracies are therefore unlikely to have introduced bias.

This survey confirms that trabeculectomy is practised by the majority of consultant ophthalmologists throughout the UK. Our estimate that 21600 trabeculectomies were performed in the year prior to the survey is comparable with Department of Health figures for England and Wales for 1994-1995. ${ }^{6}$ Assuming a glaucoma prevalence of $2 \%$ in the population over 50 years of age ${ }^{7}$ and that only half the glaucoma population is diagnosed, the population at risk is 500000 , and thus approximately $4 \%$ of glaucoma patients undergo trabeculectomy per annum.

Chronic glaucoma causes progressive visual field loss which, if left untreated, may lead to blindness. The clinical manifestations of this process are characteristic optic disc and visual field changes. IOP, inappropriately raised for the individual, is a major risk factor in the glaucomatous process. ${ }^{8-10}$ Most treatment modalities, including trabeculectomy, ${ }^{11,12}$ aim to reduce IOP. The real evidence of failure of glaucoma control, however, is not the absolute level of IOP, but the development or progression of glaucomatous field and disc changes. In this group of patients, the decision to operate was most frequently based on IOP, and in over a fifth on IOP alone. Although evidence of progressive field and optic disc

Table 6. Characteristics of non-respondents, non-participants and participants

\begin{tabular}{|c|c|c|c|c|c|c|}
\hline Response status & $n$ & $\begin{array}{l}\text { District General Hospital } \\
(\%) \text { : University Hospital }\end{array}$ & $\begin{array}{l}\text { Specialist glaucoma } \\
\text { interest }(\%) \text { : none }\end{array}$ & $\begin{array}{l}\text { Median no. } \\
\text { of years since } \\
\text { appointment }\end{array}$ & $\begin{array}{l}\text { Median no. } \\
\text { of consultants } \\
\text { in unit }\end{array}$ & $\begin{array}{l}\text { Median no. of } \\
\text { trabeculectomies } \\
\text { in year prior } \\
\text { to survey }\end{array}$ \\
\hline Participants & 382 & 270 (70.7\%): 112 & $87(22.8 \%): 295$ & 9 & 4.5 & 29 \\
\hline $\begin{array}{l}\text { Non-participants } \\
\text { Significance of difference } \\
\text { between participants and }\end{array}$ & 155 & $109(70.3 \%): 46$ & $34(21.9 \%): 121$ & 8 & 4 & 30 \\
\hline non-participants & & $p=0.934$ & $p=0.833$ & $p=0.419$ & $p=0.752$ & $p=0.859$ \\
\hline $\begin{array}{l}\text { Non-respondents } \\
\text { Significance of difference } \\
\text { between participants and }\end{array}$ & 21 & $16(76.2 \%): 5$ & $4(19 \%): 17$ & 13 & 4 & 25 \\
\hline non-respondents & & $p=0.588$ & $p=0.691$ & $p=0.206$ & $p=0.335$ & $p=0.147$ \\
\hline
\end{tabular}


Table 7. Activity analysis: variables adjusted for level of consultant activity

\begin{tabular}{lcc}
\hline Summary variable & Reported & Adjusted \\
\hline Mean age (years) & 69.2 & 68.8 \\
Mean no. pre-operative topical medications & 1.7 & 1.6 \\
Mean waiting time (months) & 62.7 & 63.2 \\
Diagnosis (\% of all cases) & & \\
POAG & $89.2 \%$ & $88.5 \%$ \\
PXE & $5.4 \%$ & $4.8 \%$ \\
NTG & $3.8 \%$ & $4.8 \%$ \\
PDS & 1.6 & 1.9 \\
IOP at diagnosis (mmHg) & & \\
All cases & 29.2 & 28.8 \\
POAG & 29.6 & 29.1 \\
PXE & 31.6 & 30.4 \\
NTG & 18.9 & 18.7 \\
PDS & 29.6 & 29.4 \\
IOP at listing (mmHg) & & \\
All cases & 26.3 & 26.2 \\
POAG & 26.5 & 26.3 \\
PXE & 29.5 & 28.3 \\
NTG & 20.0 & 19.5 \\
PDS & 25.8 & 26.1 \\
\hline
\end{tabular}

POAG, primary open angle glaucoma; PXE, pseudoexfoliation glaucoma; NTG, normal tension glaucoma; PDS, pigmentary glaucoma.

changes contributed to the decision to operate in many cases, they came second to absolute IOP. It would appear that IOP is the most influential factor when deciding to list a patient for trabeculectomy.

Primary trabeculectomy, referring to trabeculectomy as the initial treatment in a newly diagnosed case of glaucoma, ${ }^{13}$ has been advocated as it avoids visual field loss whilst attempting to control glaucoma medically ${ }^{14}$ and is more successful than delayed trabeculectomy. ${ }^{15-18}$ However primary surgery was given as the main reason to operate in only $4.8 \%$ of cases, indicating that for most cases consultants prefer to treat glaucoma medically and resort to surgery only in those where medical treatment has failed.

Advanced glaucoma, defined in this study as visual field loss involving the central $5^{\circ}$ of fixation, was present in the operated eye by the time of surgery in half the cases. That this extent of visual field loss was already present at diagnosis in $60 \%$ of this group means that glaucoma was detected late. This corroborates findings from other studies that glaucoma is often advanced at presentation ${ }^{19-21}$ and that our methods of early detection of the disease are inadequate in some cases. Of those cases where visual field loss spared the central $5^{\circ}$ of fixation at diagnosis, $30 \%$ had progressed to involve the central $5^{\circ}$ by the time of listing. Whilst these findings should be interpreted with caution because gradable visual field tests were missing in a high proportion of cases, they do suggest that visually significant field loss occurred in almost a third of patients between diagnosis and listing for surgery.

Most patients in this survey did not wait longer than 3 months for surgery. However, eyes tolerate IOP differently ${ }^{9,22}$ and what can be regarded as a safe time interval between listing a patient for trabeculectomy and surgery varies considerably between patients. A more relevant measure of appropriateness of waiting time for the individual patient is whether surgery occurred within a period stipulated by the consultant as acceptable. In $28 \%$ of this cohort the wait (allowing an additional 14 days) was longer than that considered acceptable by the consultant for that particular patient. The concern is that delay means further visual field loss, which in the case of glaucoma is generally irreversible. Adequate provision for glaucoma surgery needs to be made so that patients do not risk progression of disease whilst on a waiting list.

In conclusion, the National Survey of Trabeculectomy is a representative study of current practices of trabeculectomy in the UK. The sampling and data collection techniques have been validated and show the data are not subject to non-response, selection or reporting bias.

The data show considerable variation in practice, with IOP being the major determinant when deciding to list a patient for trabeculectomy. Although surgery occurred within 3 months of listing in $80 \%$ of patients, almost a third of consultants felt the waiting time unacceptably long. By the time of surgery approximately half the patients had advanced glaucomatous field loss in the operated eye. These findings suggest that not only should we be making efforts to detect glaucoma earlier, but that we should be aware of the risks of disease progressing to visually significant levels whilst the patient is under our care. The emphasis in treatment needs to be placed on the manifestations of glaucoma, such as disc and field changes, rather than on absolute levels of IOP. Once the decision to operate has been made, resources should be available to allow surgery to occur within a safe time interval to avoid further field loss.

\section{References}

1. Bailey CC, Sparrow JM, Grey RHB, Cheng H. The National Diabetic Retinopathy Laser Treatment Audit. 1. Maculopathy. Eye 1998;12:69-76.

2. Courtney P. The National Cataract Surgery Survey. 1. Method and descriptive features. Eye 1992;6:487-92.

3. Ridgway AEA. Trabeculectomy: a follow-up study. Br J Ophthalmol 1974;58:680-6.

4. Inaba Z. Long-term results of trabeculectomy in the Japanese: an analysis by life-table method. Jpn J Ophthalmol 1982;26:361-73

5. Fletcher RH, Fletcher SW, Wagner EH. Clinical epidemiology: the essentials. Baltimore: Williams \& Wilkins, 1982:134-5.

6. Department of Health hospital episodes statistics database. 1994/5.

7. Coffey M, Reidy A, Wormald R, Xian WX, Wright L, Courtney P. Prevalence of glaucoma in the west of Ireland. Br J Ophthalmol 1993;77:17-21.

8. Vogel R, Crick RP, Newson RB, Shipley M, Blackmore H, Bulpitt CJ. Association between intraocular pressure and loss of visual field in chronic simple glaucoma. $\mathrm{Br} \mathrm{J}$ Ophthalmol 1990;74:3-6.

9. Sommer A. Intraocular pressure and glaucoma. Am J Ophthalmol 1989;107:186-8.

10. Drance SM. Bowman lecture. Glaucoma: changing concepts. Eye 1994;6:337-45. 
11. Cairns JE. Trabeculectomy: preliminary report of a new method. Am J Ophthalmol 1968;66:673-9.

12. Watson P. Trabeculectomy: a modified ab externo technique. Ann Ophthalmol 1970;2:199-205.

13. Hitchings RA. Surgery is the treatment of choice for openangle glaucoma. Arch Ophthalmol 1998;116:239-42.

14. Jay J, Alan D. The benefit of early trabeculectomy versus conventional management in primary open angle glaucoma relative to the severity of the disease. Br J Ophthalmol 1989;3:528-35.

15. Lavin MJ, Wormald RFL, Migdal CS, Hitchings RA. The influence of prior therapy on the success of trabeculectomy. Arch Ophthalmol 1990;108:1543-8.

16. Migdal C, Hitchings R. Control of chronic simple glaucoma with primary medical, surgical and laser treatment. Trans Ophthalmol Soc UK 1986;105:653-6.
17. Broadway D, Grierson I, Hitchings R. Adverse effects of topical antiglaucomatous medications on the conjunctiva. Br J Ophthalmol 1993;77:590-6.

18. Broadway DC, Grierson I, O'Brien C, Hitchings RA. Adverse effects of topical antiglaucoma medication. II. The outcome of filtration surgery. Arch Ophthalmol 1994;1121:1446-54.

19. Pitts Crick R. Chronic glaucoma: a preventable cause of blindness. Lancet 1984;I:205-7.

20. Watson PG, Jakeman C, Ozturk M, Barnett MF, Barnett F, Khaw PT. The complications of trabeculectomy (a 20-year follow-up). Eye 1990;4:425-38.

21. Miller SJH, Karseras AG. Blind registration and glaucoma simplex. Br J Ophthalmol 1974;58:455-61.

22. Grant WM, Burke JF Jr. Why do some people go blind from glaucoma? Ophthalmology 1982;89:991-8. 